\title{
Involvement of mitochondrial and survival signaling in berberine-induced apoptosis in melanoma cells
}

\author{
Ana Burgeiro ${ }^{1,2^{*}}$, Consuelo Gajate ${ }^{1}$, El H Dakir ${ }^{1}$, Paulo J Oliveira ${ }^{2}$, Faustino Mollinedo ${ }^{1}$ \\ From 16th International Charles Heidelberger Symposium on Cancer Research \\ Coimbra, Portugal. 26-28 September 2010
}

Here, we have found that the natural isoquinoline alkaloid berberine induced apoptosis of SK-MEL-2 human melanoma cells, as assessed by an increase in sub-G1 phase (hipodiploidy) in flow cytometry analysis, which involved mitochondria and caspase activation, including caspases $3,4,7,8$, and 9. Berberine induced disruption of the mitochondrial transmembrane potential $\left(\Delta \Psi_{\mathrm{m}}\right)$, released cytochrome $c$ and AIF from mitochondria, as well as increased reactive oxygen species (ROS) production and decreased the ATP/ADP ratio. Ectopic Bcl- $\mathrm{X}_{\mathrm{L}}$ overexpression inhibited berberineinduced cell death, $\Delta \Psi_{\mathrm{m}}$ loss, cytochrome $c$ and AIF release, and ROS generation, thus demonstrating the involvement of mitochondria in the cell death process. Berberine also led to the generation of the p20 cleavage fragment from BAP31, involved in the directing proapoptotic signals between endoplasmic reticulum and mitochondria. Inhibition of ERK phosphorylation, by using the MEK inhibitor PD98059, significantly reduced the berberine concentration required to promote apoptosis. Reduction of the level of BRAF by silencing RNA promoted cell death of melanoma cells and increased berberine-induced apoptosis. These data reveal the involvement of mitochondria in berberine-induced apoptosis in melanoma cells, and the implication of additional signaling processes, such as survival ERK and BRAF signal cascades, that once inhibited facilitate the cell death response triggered by berberine. The results provide novel insights into the mechanisms of berberine-mediated anti-melanoma activity.

\section{Acknowledgments}

This work was supported by grants from the Fundação para a Ciência e Tecnologia (FCT, Portugal): PTDC/QUI-QUI/101409/2008 (to P.J.O.) and SFRH/ BD/32943/2006 (to A.B.); Ministerio de Ciencia e Innovación (Spain): SAF200802251, and RD06/0020/1037 from Red Temática de Investigación

Cooperativa en Cáncer, Instituto de Salud Carlos III, cofunded by the Fondo Europeo de Desarrollo Regional of the European Union (to F.M.); Fondo de Investigación Sanitaria and European Commission: PS09/01915 (to C.G.); Junta de Castilla y León: GR15-Experimental Therapeutics and Translational Oncology Program, and Biomedicine Project 2009 (to F.M.); C.G. is supported by the Ramón y Cajal Program from the Spanish Ministerio de Ciencia e Innovación.

\section{Author details}

'Instituto de Biología Molecular y Celular del Cáncer, Centro de Investigación del Cáncer, Consejo Superior de Investigaciones Científicas (C.S.I.C.) -

Universidad de Salamanca, Campus Miguel de Unamuno, Salamanca, Spain\. ${ }^{2}$ Center for Neurosciences and Cell Biology, Department of Life Sciences, University of Coimbra, Coimbra, Portugal.

Published: 24 September 2010

\section{doi:}

Cite this article as: Burgeiro et al: Involvement of mitochondrial and survival signaling in berberine-induced apoptosis in melanoma cells. BMC Proceedings 2010 4(Suppl 2):P15.

\footnotetext{
* Correspondence: ana_burgeiro@hotmail.com

'Instituto de Biología Molecular y Celular del Cáncer, Centro de Investigación del Cáncer, Consejo Superior de Investigaciones Científicas (C.S.I.C.) -

Universidad de Salamanca, Campus Miguel de Unamuno, Salamanca, Spain\ Full list of author information is available at the end of the article
} 